\title{
SAND $-95-3047$
}

\section{RECEIVED}

MAY 151996

OSTI

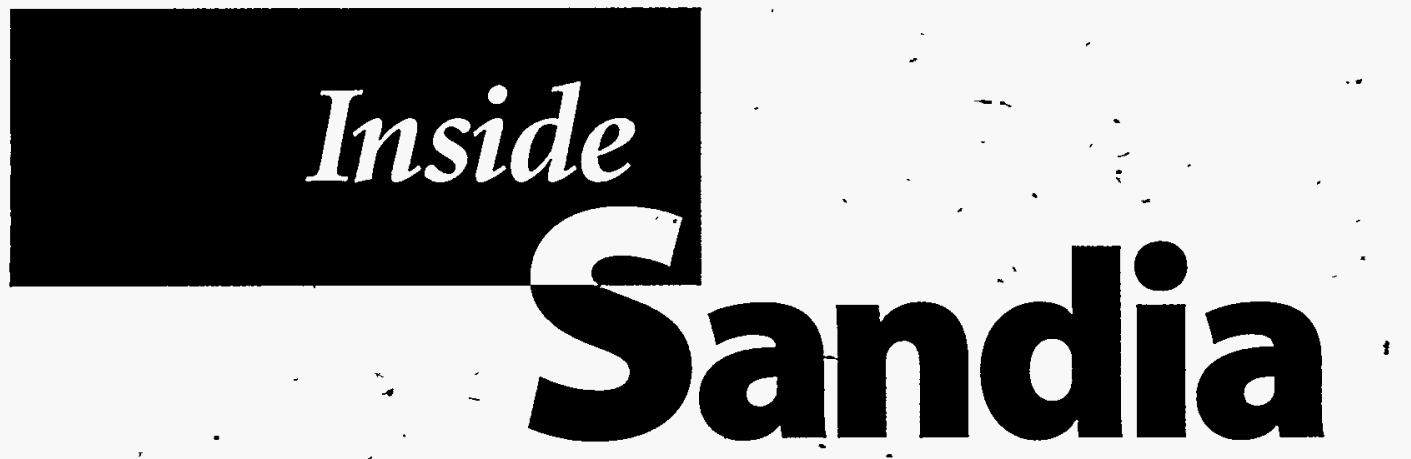


Published by Sandia National Laboratories

Sandia is a multiprogram engineering and science laboratory operated by Sandia Corporation, a Lockheed Martin company, for the Department of Energy, witl major facilities at Albuquerque, - New Mexico, and Livermore, California. Sandia has major research and development responsibilities for nuclear weapons, arms control, energy, the environment, economic competitiveness, and other areas of importance to the needs of the nation. The Laboratories' principal mission is to support national defense policies by ensuring that the nuclear weapon stockpile meets the highest standards of safety, reliability, security, use control̀, and military performance. 


\section{J A N U AR Y 1996}

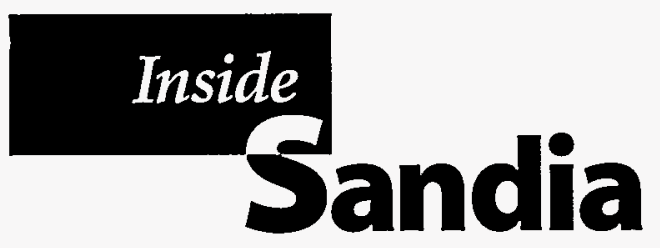

\section{Contents}

$\begin{array}{lr}\text { Previews } & 2\end{array}$

Newsbrief: Molten salt corrosion testing 3

Pulsed ion beams for thermal surface treatment $\quad 4$

$\begin{array}{ll}\text { Unmasking hidden armaments } & 6\end{array}$

Charbroiled burgers, heterocyclic amines, and cancer $\quad 8$

Newsbrief: Revolutionary airbag offers increased safety options $\quad 10$

Newsbrief: EcoSys ${ }^{7 t}:$ an expert system for'Green Design' 11

Sandia, salt, and oil $\quad 12$

Newsbrief: Automated fixture design speeds development for prototypes and production

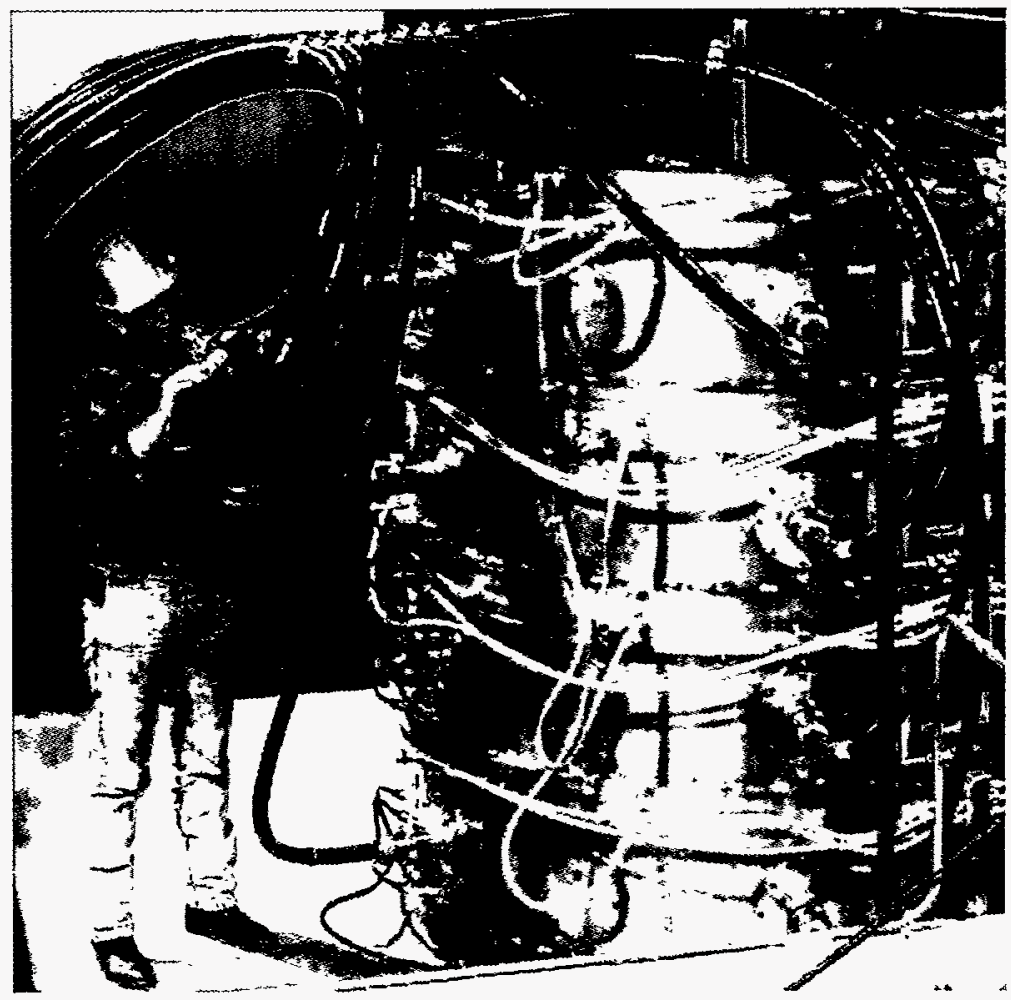

The pulsed-ion beam machine that demonstrated a thermal surface treatment technique that may have wide commercial applicability. See article on page 4. 


\section{From a new surface treatment method to U.S. oil storage}

\section{Our second issue looks at a variety of innovations from Sandia Labs}

his issue of Inside Sandia covers a wide range of technologies at Sandia National
Laboratories. The first article is on a new method for surface treatments of a variety of materials, with an initial emphasis on metals and alloys. Pulsed ion beams can improve the smoothness, hardness, and durability of materials at a potentially lower cost than other surface treatment methods.

Other articles in this issue include a study of heterocyclic amines (special compounds found in cooked foods) and their relationship to cancer. Sandia's computer modeling skills and supercomputer facilities have contributed to a better understanding of how mutagens (cancer-causing chemicals that interact with DNA) operate. The article on a new arms control instrument reports on a technique that utilizes superconducting materials to detect minute variations in the Earth's gravity field, variations that can reveal the presence of nuclear weapons or hidden facilities.

The final article in this issue examines Sandia's contributions to the United States' Strategic Petroleum Reserve, a reserve of several hundred million barrels of oil that protects the country from oil embargoes or other emergencies. Sandia's long involvement in engineering and computer modeling at the SPR was invaluable in a recent situation that could have had a significant environmental impact. The Department of Energy used Sandia's capabilities to provide information on how to respond to the sinkhole at Weeks Island.

Over 500 people and institutions who receive Inside Sandia have returned their mailers from the first issue, requesting that they remain on the subscription list for the magazine. In this issue and the next, we will remind you to send in those mailers (or subscribe through the contact points provided below) to continue receiving your free copies of this magazine. If the articles and newsbriefs published here are useful to you or your company, if information on the latest technologies developed at Sandia is important to you, be sure to let us know, and we will keep sending this publication to you. Thank you for your response.团 


\section{Newsbrief}

\section{Molten salt corrosion testing}

Three million pounds of molten salt. That's the fundamental difference between two solar "power tower" plants in southern California. Solar One generated pollution-free, power-grid-grade electricity from 1982 to 1988, and now Solar Two has been built on the same site as Solar One. The new 10-megawatt plant uses many of Solar One's components (heliostats, central tower, and turbine generator), but, unlike Solar One, Solar Two will use a molten nitrate salt mixture for thermal storage, allowing power production on demand, even when sunlight is unavailable.

In a program sponsored by DOE's Office of Solar Thermal, Biomass, and Geothermal Technologies, chemical engineers Bob Bradshav and Mike Prairie, with other Sandia solar engineering and materials specialists, pondered one remaining question: could commercial-grade nitrate salts, with their traces of chlorides and other impurities, be safely contained with affordable stainless and carbon steels, even when subjected to temperatures that cycle daily between $290^{\circ} \mathrm{C}$ and $560^{\circ} \mathrm{C}$ ?

The answer was "yes." Tests at Sandia's Molten Salt Corrosion Testing Laboratory replicated 1.5 years of operation at Solar Two and demonstrated that Type 316 stainless steel possesses good corrosion resistance and that less expensive carbon steel can be used for the lower-temperature salt-containment components. "We found that a thin corrosion-resistant oxide layer builds up on exposure to sodium-nitrate/potassium-nitrate salt mixtures," said Bradshaw; "and the integrity of this layer is not significantly compromised by either impurities in commercial-grade salts or the stresses induced by daily thermal cycles." Using these economical materials can help the technology become a costcompetitive alternative to fossil-fuel power plants. Other research on molten salt heat exchangers showed that chromium-molybdenum steel alloys could be improved for solar technology use by enriching the alloy with inexpensive silicon.

Sandia's Molten Salt Corrosion Testing Laboratory is also available for use for appropriate research or testing efforts that might be needed by other industry researchers.团

For more information, call:

Bob Bradshaw, Materials Chemistry, (510) 294-3229, or

Mike Prairie, Solar Thermal Technology, (505) 844-7823.

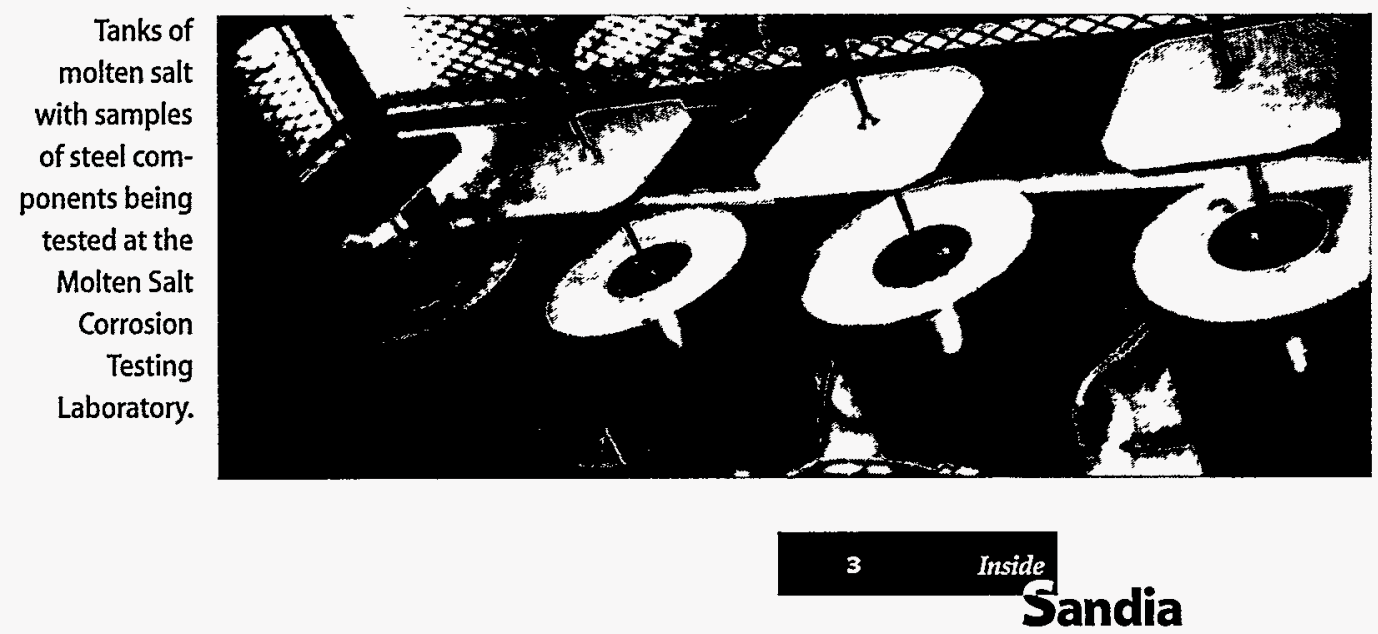




\section{Pulsed ion beams for thermal surface treatment}

\section{Improved corrosion, wear, and hardness properties at low cost}

$\mathrm{F}_{\text {a material's outer surface can improve its hardness and resistance to corrosion }}^{\text {or the past } 40 \text { years, researchers have studied how melting and rapidly solidifying }}$ and wear. However, because of its expense and the difficulties involved in applying this technique to surfaces, the technology is not widely used in industry for surface treatment.

Recently, Sandia plasma physicists and materials scientists have teamed with Cornell University to develop a novel, commercially attractive technology called Ion BEam Surface Treatment, or IBEST, which promises to reduce drastically the cost of surface treatment by rapid solidifications.

IBEST uses high-energy, pulsed ion beams to deposit energy directly in the top 2 to 50 microns of a material. The high instantaneous power ( 1 to 100 billion watts) ion pulses, lasting approximately 0.1 microsecond each, melt a thin top layer of the material. The flow of heat into the underlying metal causes the melted material to cool almost instantly.

"IBEST's cooling rate is so fast that the surface returns to room temperature in a few microseconds, allowing the surface to cool between pulses, even though the pulses occur as rapidly as 120 times per second," explains Bob Turman, a Sandia plasma physicist who is leading the IBEST demonstration and commercialization initiative.

Commercial possibilities for this technology are very broad. To date, Turman and Sandia materials scientists have identified IBEST as a practical, inexpensive way to improve the endurance of components in applications such as chemical reactor

Gary Pena, Sandia pulsed power technician, checks high-power lines leading to the pulsed-ion beam machine that first demonstrated the feasibility of commercialscale uses of the surface treatment technique.

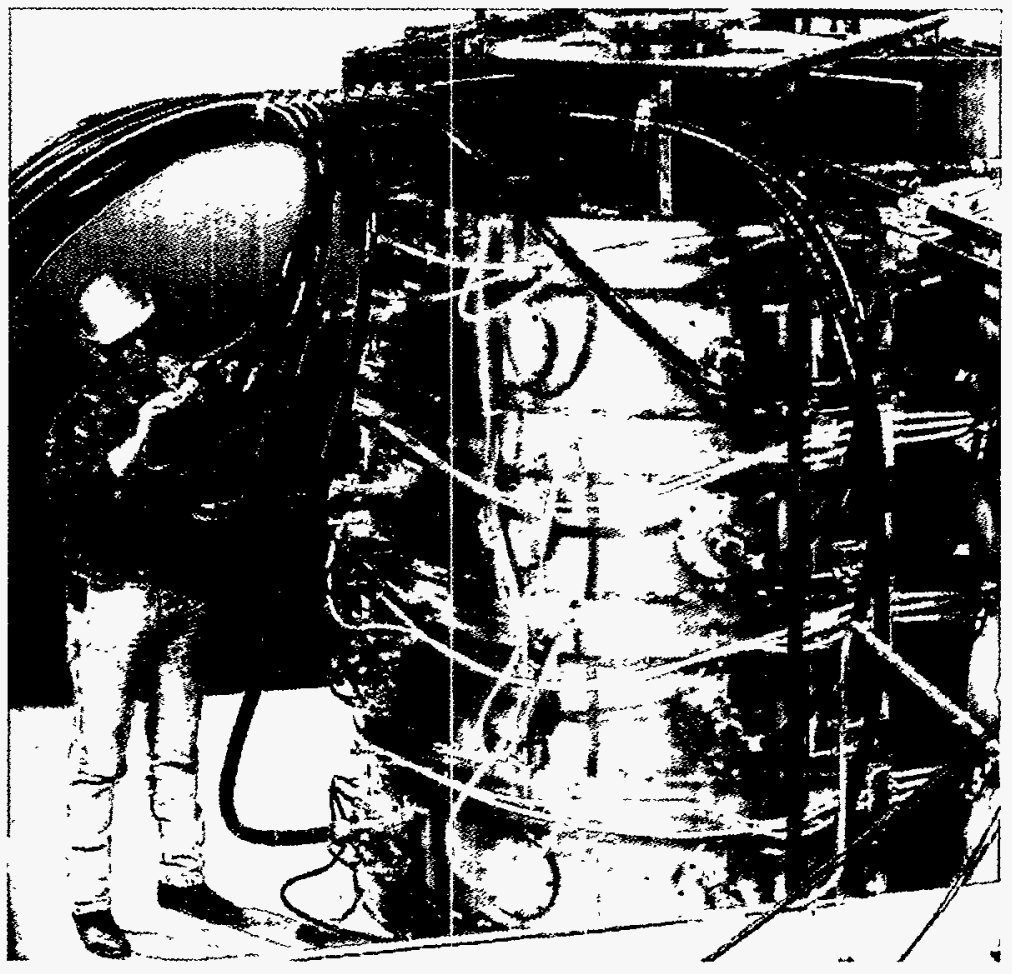


vessels, jet turbines, heat exchangers, gear boxes, and tools and dies. Even medical hip- and knee-joint implants could be made more resistant to corrosion, hardened, and smoothed using IBEST. Chemical-free surface cleaning and polishing, and sealing of ceramic surfaces are other promising IBEST applications.

Today, components for these applications, as well as scratch-resistant plastic surfaces, are either made of costly metal alloys or treated with hazardous heavy metals and ozone-depleting solvents. "Because IBEST pushes the onset of chemical pitting out to much more corrosive environments, chemical processors could use inexpensive IBEST-treated metals instead of a more expensive anticorrosive alloy or an environmentally undesirable process such as chromate plating," observes materials scientist Rudy Buchheit. Adds Dale McIntyre, a former member of the Sandia IBEST team, "Substituting IBEST technology for just one-fifth of existing surface treatment and cleaning processes would eliminate the use of 20,000 metric tons of toxic heavy metals and 50,000 metric tons of hazardous solvents in the U.S. each year."

"In the past four years, we've merged two new technologies to make IBEST surface treatment possible," Turman notes. The first technology is repetitive pulsed power, which Sandia’s Repetitive Pulsed Power Department has pioneered for such applications as materials treatment, weapons studies, inertial confinement fusion, electronic food pasteurization, and waste water treatment. The second technology is repetitive ion-beam systems, which Cornell researchers developed in the late 1980s. Sandia is already operating one IBEST machine, called the Repetitive High Energy Pulsed Power-I facility, where experiments have confirmed IBEST's potential. "The IBEST team also includes Los Alamos, Cornell, and the University of New Mexico," adds Gene Neau, manager of the Repetitive Pulsed Power Department.

A next-generation IBEST system is under development, with a goal of $15 \mathrm{KW}$ average ion power. The high-power efficiency inherent in such a system, coupled with its high throughput capability, would make processing costs competitive with, or even lower than, current surface treatment processes. The developers envision uses of scaled-up IBEST equipment that range from treatment of high-value medical implants to treatment of the entire output of a rolling mill.

The IBEST team, which has completed an internally funded three-year development program, is now working with industrial partners to identify the most promising commercial applications for ion-beam surface treatment. "Also, we'd like to work with equipment manufacturers to put a small-scale IBEST system in every major university in the country, so researchers and graduate students can work on developing new processes and applications of IBEST,' concludes Turman.

For more information, call:

Bob Turman, Ion Beam Surface Treatment Program, (505) 845-7003, or Rudy Buchheit, Mechanical and Corrosion Metallurgy, (505) 844-6904. 


\section{Electronics}

\section{Unmasking hidden armaments}

\section{Superconducting gravity sensor could find underground weapons, bunkers}

CC ou can hide something by painting it the same color as its background, by min-

1 imizing its radar reflection or making it throw back random radar pulses, or by sealing it in a lead box. But you can't hide the gravitational field it generates," says Sandian Rob Duncan. "You can't 'stealth' gravity."

The gravitational signature of a truck, a tank, or a nuclear warhead is infinitesimal, compared to the earth's gravity. But Duncan and a team of investigators are developing new field-deployable superconducting accelerometers to add gravity to the optical, radar, X-ray, neutron, and other methods that help verify arms-control treaties or, in wartime, ferret out an enemy's armaments and underground fortifications.

The earth's internal churning creates gravitational noise thousands of times as strong as the signals that are being sought. But by combining two accelerometers in one instrument and cancelling the common-mode noise that both detect, it's possible to create a gravity gradiometer that responds only to close-by variations in the gravitational field. "If the two accelerometers are 15 centimeters apart," explains Duncan, "the Earth's gravitational noise, originating many kilometers away, will be the same at both accelerometers and will be ignored." But the mass of a vehicle a few meters away - or the absence of mass caused by a tunnel or underground

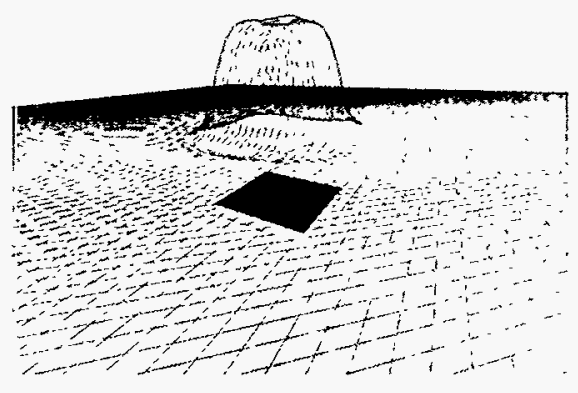
bunker - affects each accelerometer differently and reveals that something is hidden.

The first-generation Sandia instrument, developed in an internally funded project, is a cylinder about one meter long and 20 centimeters in diameter. It weighs less than 10 kilograms, including a liquid-helium reservoir that can keep the superconducting material chilled for two days.

Superconducting materials allow a great increase in sensitivity over conventional instruments. Along with niobium for electrical and mechanical parts, the gradiometer uses SQUIDs - superconducting quantum interference devices

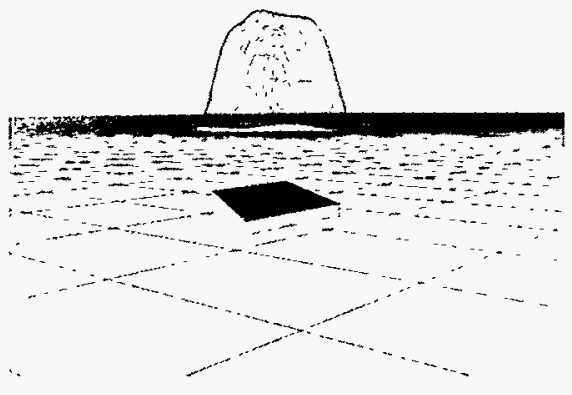
- as supersensitive transducers to detect movements of proof masses in the instrument as they respond to gravitational fluctuations. Nonsuperconducting gradiometers are much larger and heavier, and they're less sensitive. 
The methods used to fabricate the Sandia instrument are environmentally benign. Because niobium is difficult to machine conventionally, Sandia developed innovative methods of electric discharge machining to shape parts, as well as electron beam welding methods to join them. Other fabrication methods exist, but they require toxic materials.

When the design of the field-deployable gradiometer is improved (in part through a collaboration with the University of Maryland) to take fuller advantage of the superconducting materials' potential, the instrument should routinely be able to detect targets of military significance both above and below
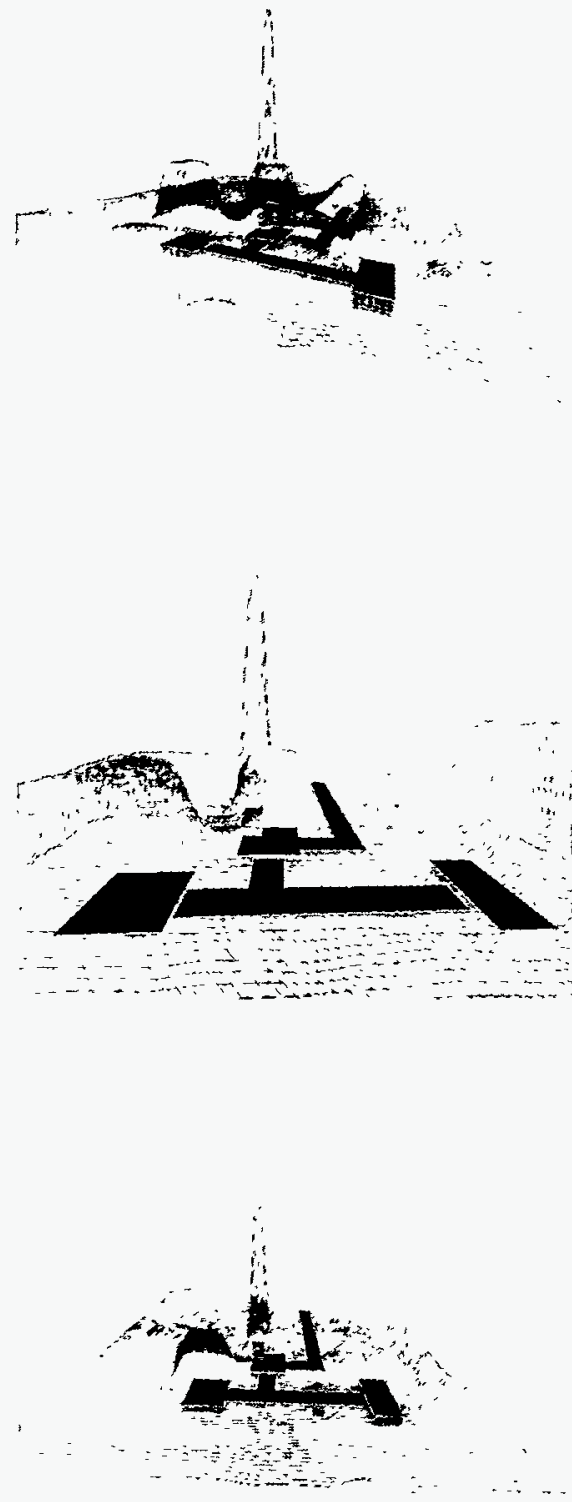

the ground. For treaty verification, inspectors could scan a missile and the gradiometer would reveal whether it contained a conventional armament or a nuclear warhead. Coupled with other sensing methods, such as synthetic aperture radar, and including a computer system to separate gravitational clutter from objects of interest, the gradiometer could add a hitherto almost-unused physical force to defense-related sensing capabilities. "Someone might hide fissile material in a concealed lead vault to fool a Geiger counter," says Duncan, "but a gravity gradiometer would detect the suspicious presence of that massive vault." Besides defense applications, field-deployable gravity gradiometers could aid exploration for minerals, oil, and gas. They could even track the rise and fall of a water table or the spreading underground plume of a contaminant.

Superconducting device technology similar to that used in the gravity gradiometer is also proving useful for more fundamental scientific research. Duncan is principal investigator of the Critical Dynamics in Microgravity experiment (also involving the University of New Mexico, NASA's Jet Propulsion Laboratory, and Caltech) now being defined for a space shuttle flight. 团

For more information, call:

Robert Duncan, Optics and Exploratory Technologies, (505) 844-4833, or Andy Boye, Optics and Exploratory Technologies, (505) 845-8175.

Computer simulation and illustration of the gravitational signatures created by various underground objects, ranging from a simple bunker to a massive complex.These simulations were created using Sandia's Multidimensional, User-oriented Synthetic Environment — MuSE. 


\section{Charbroiled burgers, heterocyclic amines, and cancer}

\section{Molecular modeling identifies dangerous mutagens}

$\mathrm{D}_{\mathrm{s}}$

o you really enjoy that charbroiled hamburger? Is a well-done steak with the grill pattern seared into it your idea of heaven? Unfortunately, such foods may have carcinogenic effects. Sandia's Scientific Computing Department, with funding from Lawrence Livermore National Laboratory's Biology and Biotechnology

Research Program, is studying why foods cooked over high heat could be dangerous.

When food is cooked over high heat, compounds called heterocyclic amines are formed, which are not themselves carcinogenic. However, when the body metabolizes the heterocyclic amines, certain highly active compounds, or mutagens, are formed. A mutagen is any substance that chemically alters DNA - - and chemically altered DNA can lead to cancer. However, not all mutagens are the same.

"These compounds are chemically very similar," explains Michael Colvin, one of the project's lead investigators, "but there's an enormous range of potency among them. Certain mutagens are much more likely to lead to cancer, while others remain relatively harmless." The potency of one mutagen can be as much as a million times greater than the potency of a chemically similar cousin. Sandia chemists are using sophisticated molecular modeling capabilities to help determine why certain mutagens are more dangerous than others.

Colvin and his associates use a powerful molecular modeling program, $\mathrm{QC}++$, to examine the mutagenic compounds. Developed by Curtis Janssen and Ed Seidl, QC++ is a massively parallel quantum chemistry program that enables the computer to probe simulated molecules in ways that complement more traditional laboratory methods. Chemists use the program to calculate properties of molecules and predict chemical reactions from first principles. The program runs on Sandia's Intel Paragon supercomputer, a massively parallel machine operated by Sandia's Massively Parallel Computing Research Laboratory.

The process begins by generating computer models of the heterocyclic amines. Next, the scientists model the metabolites - what the compounds become after the body chemically transforms them. To model both the compounds and the metabolites, the Sandia researchers solve the molecular Schroedinger equation, which can calculate any measurable quantity in a compound, ranging from structure to light absorption. For the heterocyclic amine work, the quantities of interest are the structure - the length of the bonds between the atoms - and how much energy it takes to form the metabolites. Using these figures, scientists can then begin to analyze results, looking for any patterns that might indicate why one metabolite is 


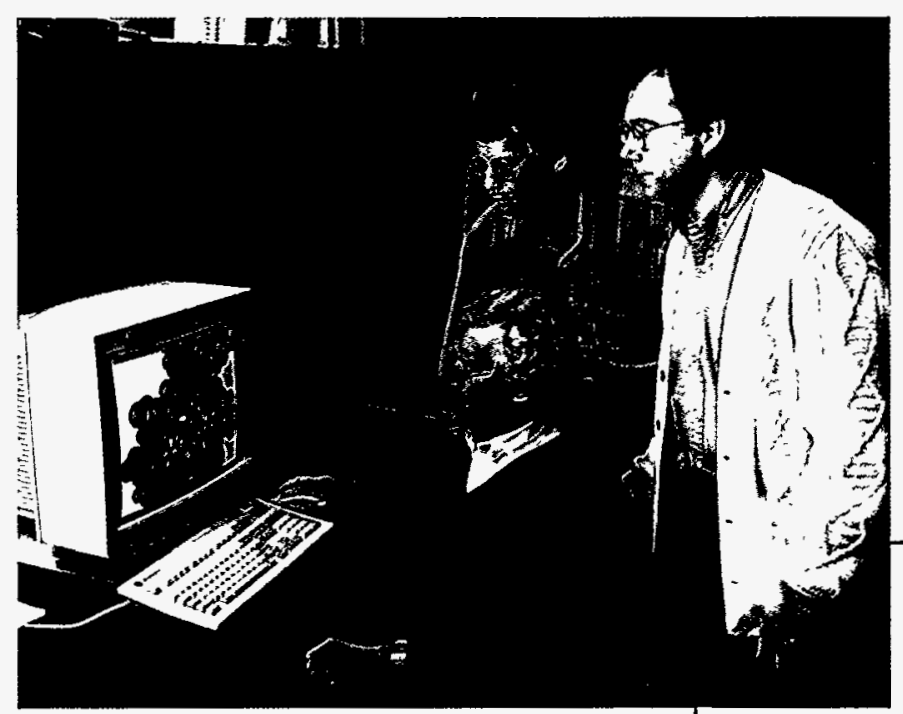

DNA Binding Pathways for AlA Mutagens

TOP: Carl Melius (seated), Curt Janssen (rear), and Mike Colvin examine a computer-generated model showing the structure of a molecule binding to DNA. The computational chemistry programs developed at Sandia can reveal the reactive characteristics of compounds in simulated human biochemistry. RIGHT: Examples of different pathways that can lead to AlA mutagens binding to DNA. Differences in mutagenic potency can be manifested at any of the steps shown.

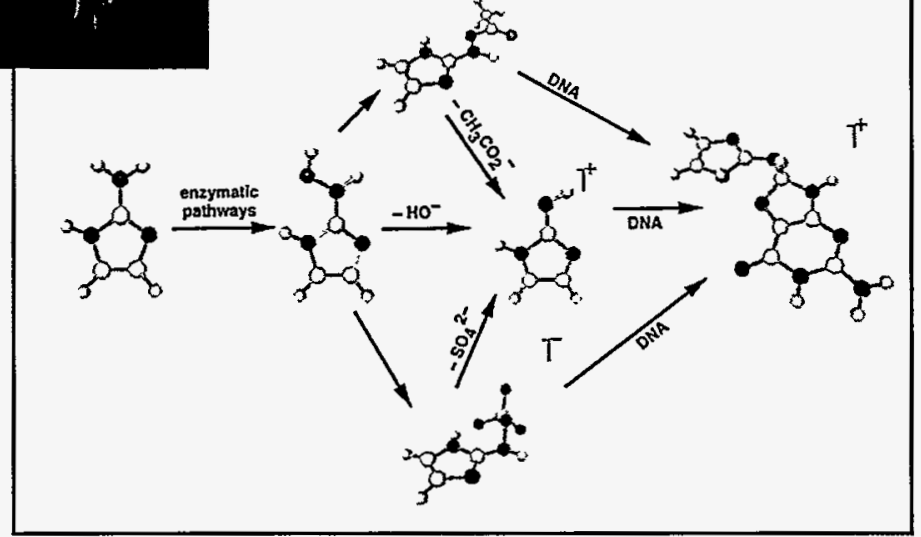

carcinogenic while another is not. Calculations on the Paragon computer have produced several correlations between computed chemical properties and mutagenicity. More than 50 mutagens have been examined, and Lawrence Livermore scientists are working with the results in laboratory experiments.

According to Colvin, both this project and molecular modeling in general have applications beyond the field of biotechnology. Other groups within Sandia use molecular modeling to improve processes in areas such as oil exploration and environmental research. Still others seek to improve products ranging from tires to aluminum alloys to semiconductor materials. Meanwhile, researchers in the Scientific Computing Department continue to study heterocyclic amines, modeling molecules so that we can better understand how items such as a charbroiled hamburger may increase the chance of developing cancer. 团

For more information, call

Michael Colvin, Scientific Computing, (510) 294-2728, Curtis Janssen, Scientific Computing, (510) 294-1509, or

Ed Seidl, Scientific Computing, (510) 294-3693.

BACKGROUND: Molecular models of mutagenic compounds (called AIA mutagens) formed when food is cooked. Such compounds are found in small amounts in most cooked foods, but cooking red meat creates much larger quantities of such mutagens. 


\section{Revolutionary airbag offers increased safety options}

Sandia's parachute development engineers have worked with Precision Fabrics Group, Inc., to create a revolutionary automotive airbag. The new technology reduces both the volume and weight of an airbag more than $60 \%$ compared to airbags currently installed in passenger vehicles. The joint project, based upon a cooperative research and development agreement, or CRADA, began in 1992.

"Reducing the size and weight of an important automobile component by almost two thirds over three years is a significant advance", says Carl Peterson, one of the Sandia researchers involved in the project. "That accomplishment shows how relevant our R\&D base is, when applied to the right projects." Sandia has over four decades of experience in developing and packaging high-performance, lightweight parachutes for defense missions.

Precision Fabrics Group is the world's largest manufacturer of military personnel parachute fabrics. As Lanty Smith, the company's $\mathrm{CEO}$, notes, "Basic airbag design and science hadn't been rethought in a quarter century. Our joint approach with Sandia was to understand the basic science and then create the most efficient and cost-effective products to meet the automotive industry's needs." Precision Fabrics has a proprietary interest in the new technology for automotive airbag use.

When folded, the new airbag can fit into a man's shirt pocket, while conventional designs are about the size of

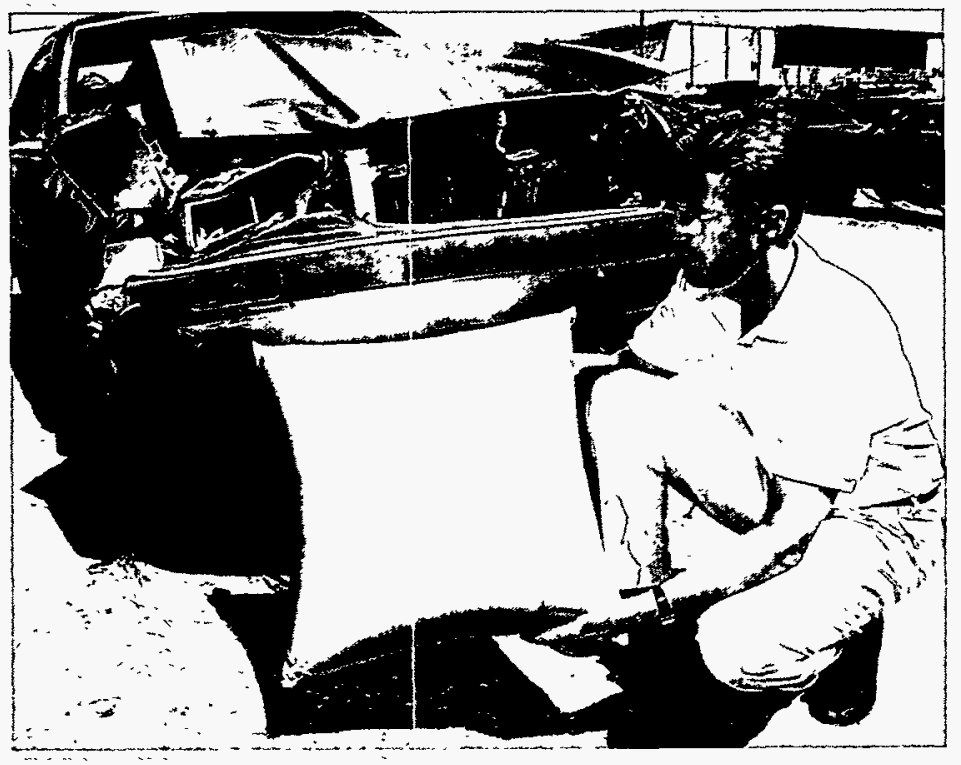

Sandia researcher Kenneth Gwinn displays a prototype of the compact, lighter airbag developed by Sandia and Precision Fabrics Group. two stacked videocassettes. The reduced size of the PFG airbag can allow the use of more airbags in vehicles, such as in door panels and all passenger areas. The new design is expected to have a major impact on the airbag market. As Peterson also notes, "Sandia's expertise in this area can be applied to impact attenuation requirements for uses that no one may have thought of before such small devices were available."

For more information, call: Carl Peterson, Unsteady and Reactive Fluid Mechanics, (505) 844-6775. 


\section{EcoSys $^{\mathrm{T} \mathrm{M}}$ : an expert system for 'Green Design'}

EcoSys is a computer program that contains material science information and process engineering knowledge and provides the view'points of environmental policy experts. Randy Watkins, a Sandia researcher and environmental consultant, created the program when he was inundated with environmental impact questions. "There was a lot of information on solvents, soldering, and machining that I kept repeating," recalls Watkins. "I soon figured out that an expert system could provide these answers."

EcoSys supports "green design" - design for manufacturing that does minimal damage to the environment. The program is rated highly by potential users. Both SEMATECH, the consortium of semiconductor manufacturers, and the National Center for Manufacturing Sciences have evaluated EcoSys very favorably. Mike Wixom, formerly of NCMS, describes EcoSys as"a systematic, proactive way to control the environmental costs of manufacturing during early product design and process planning."

EcoSys already contains the knowledge of process engineers from DOE's AlliedSignal plant in Kansas City who are involved in the fabrication of printed wire assemblies, cables, and machined metal parts. "EcoSys is one of the few green design decision support tools that is not an empty shell, that has real process data to back it up," says Wixom. Other process knowledge can be moved into the program as the system matures.

Besides process information, EcoSys embeds the viewpoints of environmental policy analysts, offering a range of compliance/design options. "This component of EcoSys addresses the subjective nature of environmental impact analysis," says Ted Wheelis, Sandia's manager for further development of EcoSys. "It can point to the best product design for manufacturers who seek solely to comply with regulations, or it can identify optimal designs for manufacturers who want to address more global environmental issues."

Many applications are anticipated for EcoSys as it becomes more widely used. Real-time product realization teams could use it early in a product development cycle. It could also be used to analyze existing environmental liabilities of a given product and direct how research and development could reduce the impact of those processes. 团

For more information, call:

Ted Wheelis, Environmentally Conscious Life Cycle Systems,

(505) 845-9298. 


\section{Sandia, salt, and oil}

\section{Labs' diagnostics and analysis help maintain vital U.S. oil reserve}

W

eeks Island, Louisiana, 1992.

At the edge of this storage site of the U.S. Strategic Petroleum Reserve, a sinkhole was found that measured 11 meters across and 9 meters deep. This anomaly at the surface of the site raised questions about possible effects on the storage cavern at Weeks Island, which was converted from an old "room and pillar" salt mine last operated by Morton Salt Company. Working closely with the Department of Energy's Strategic Petroleum Reserve Program and the SPR O\&M contractor, DynMcDermott, Sandia engi-

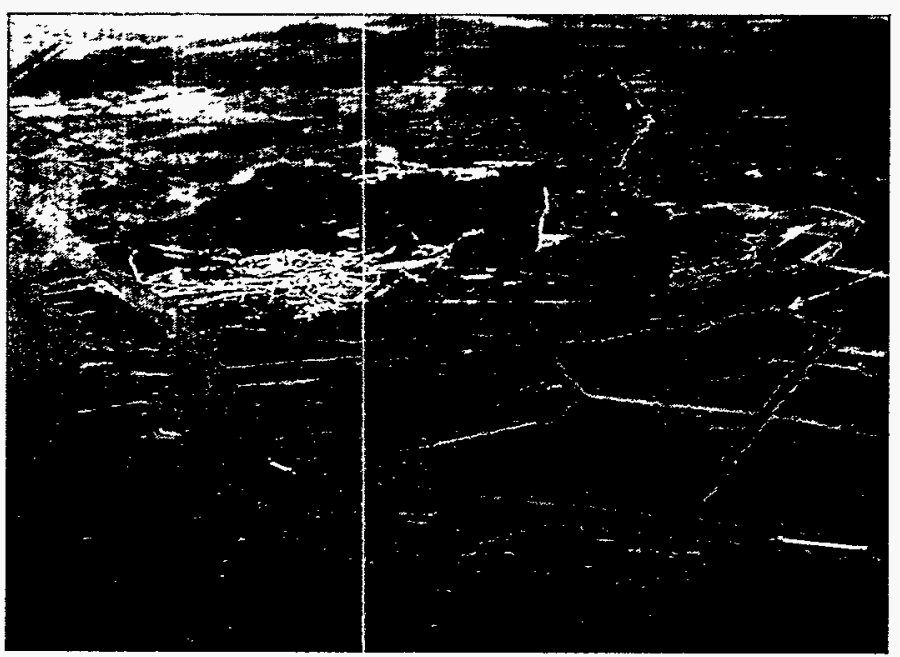

Aerial view of the Weeks Island site, which includes both salt-mining operations and oil storage activities. The coastal areas of Louisiana and Texas provide the salt-dome formations used by the Strategic Petroleum Reserve. neers and scientists applied diagnostic and analytical techniques to determine the cause and possible effects of the sinkhole.

Sandia's capabilities in working this geological problem were based on long experience in supporting oil storage in salt domes. The first strategic U.S. oil reserves were established in 1975 and developed by the Strategic Petroleum Reserve Program. Three years later, DOE asked Sandia for research and engineering assistance. "DOE asked us to evaluate the very first caverns. We explored their structural features and then analyzed the impact of cavern excavation on the earth's surface," says James Linn, manager of Sandia's Underground Storage Technology Department.

Sandia research and analytical support for the SPR drew upon a broad range of skills from the Labs. Geology, hydrology, computer simulation, chemistry, and other disciplines and functions helped build an understanding of the effects of oil storage in salt dome caverns in the largest storage project of its kind ever undertaken.

The Strategic Petroleum Reserve was established after the Mid-East oil embargo of 1973. During the embargo, drivers were forced to pay high gasoline prices, wait in long lines, and search for open stations. In contrast, when Kuwait and Iraq stopped producing oil during the Persian Gulf War, there was no "oil crisis." By authorizing the withdrawal of 5\% (30 million barrels) of its oil reserves, the U.S. helped stabilize world oil prices, demonstrating the usefulness of SPR and the need for continued long-term oil storage.

The storage caverns are located in naturally occurring underground salt 
Stew Thompson, a geotechnical engineer with Acres International, a Sandia contractor, examines a salt cavern near the Weeks Island oil storage facility. Created by salt mining operations, Weeks Island suffered an inlet of fresh water that created a local sinkhole. domes that are 5 to 10 miles deep and up to 5 miles across. Although nature provides the storage sites, engineers must create uniform, reusable oil caverns within the huge salt domes, either by using existing salt mines or by leaching new caverns. The Underground Storage Technology Department found that the shape and size of a leached cavern could be controlled by the vertical relationship of two pipes suspended in wells drilled deep into a salt dome. One pipe pumps in fresh water while the other pipe pumps out salt brine; the process dissolves the salt and creates a cavern. As more fresh water is pumped in, the cavern expands.

"If the inlet and outlet pipes are too close together, a bulb forms at the bottom of the cavern. If the pipes are separated too far, the cavern becomes too long," says Linn. The preferred shape - that of a stubby carrot - gives the cavern structural stability, large amounts of storage space, the least amount of salt closure (also known as salt creep), and the potential to be reused. To help engineers place the pipes correctly (to create the preferred carrot-shaped cavern), Sandia engineering scientist Anthony Russo developed SANSMIC (Sandia Solution Mining Code), a modeling code for creating uniformly shaped caverns.

Weeks Island used a different approach to oil storage. A former salt mine with huge rooms hollowed out by mechanical excavation, the site was converted to oil storage during the first years of the SPR. Almost 20 years later, the sinkhole appeared, and Sandia was asked to help find out why. Sandia's work confirmed the theory that fresh water was seeping into the salt mine, while computer analysis and modeling suggested strongly that the process could occur in other locations around the site. Empirical data, including the appearance of a second, smaller sinkhole, confirmed Sandia's analysis. With this information in hand, DOE decided that the best solution 


\section{Energy (cont'd.)}

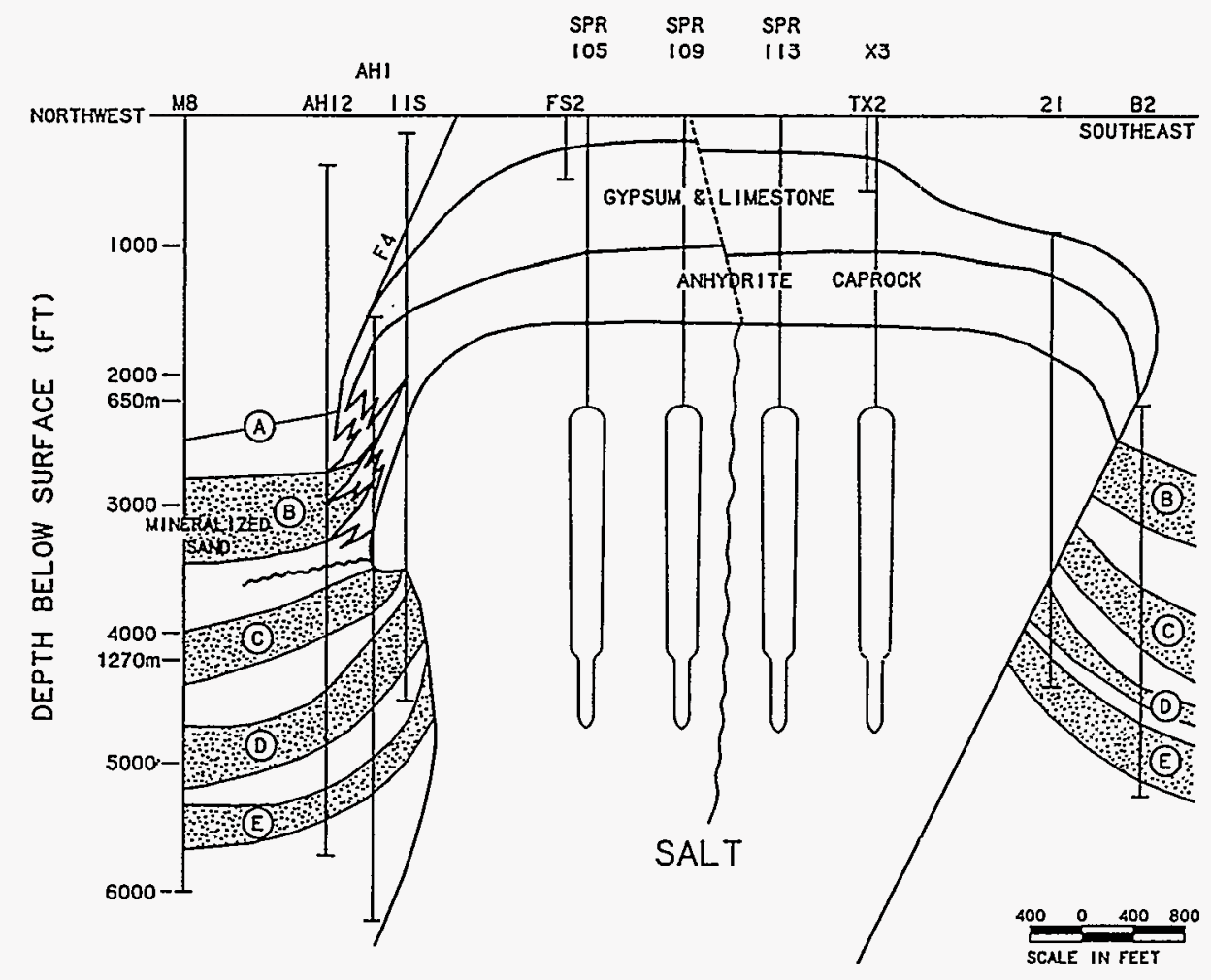

would be to close the Weeks Island site

Diagram of Big Hill, Texas, salt dome with four oil storage caverns leached into the salt formation. and remove all oil from its cavern. Fourteen caverns will be leached into this dome to

Emptying the cavern at Weeks Island is hold 160 million barrels of oil. not just a matter of pumping out the oil that is there - something has to take its place. What goes in is brine that is completely saturated with salt. This saturated brine fills up the caverns and keeps the surrounding salt from dissolving, while the fluid pressure keeps the cavern from gradually closing in and perhaps affecting the surface geology.

Pumping the oil out of leached cavern storage sites is not so simple, either. The oil has heated up while stored in caverns that may be 2,000 feet deep, and it has absorbed small amounts of gas, mostly methane, from the surrounding salt, where the gas was held in the minute spaces between salt grains. Whether a cavern is emptied as a precautionary environmental measure, as is occurring at Weeks Island, or during a drawdown to meet national security interests, the effects of storage have to be taken into account. Sandia scientists and engineers have developed algorithms to predict these effects and engineering/transportation procedures to ensure personal and environmental safety, as well as to decrease the risk of damage to pumps and storage tanks. 
As James Linn notes, "Underground storage of hydrocarbons, at SPR and elsewhere, is much safer because of SPR's experience and Sandia's contributions." Furthermore, the knowledge Sandia has gained at SPR is finding applications far afield from the salt domes on the Gulf coast. Sandia's experience there is synergistic with the Labs' work at the Waste Isolation Pilot Plant in southeast New Mexico, where proposed radioactive waste storage in an underground bedded salt formation is being studied. Jim Neal, one of Sandia's SPR researchers, says that Sandia's flow meter technology (used in studying the sinkhole) has applications both at SPR and elsewhere, and there are many other elements of the technology at SPR, such as Sandia's geotechnical engineering, computational modeling, fluid dynamics, and materials technologies, that have attracted interest, including potential work with the natural gas industry.

The Strategic Petroleum Reserve program has lived up to its promise of safeguarding the U.S. against oil embargoes and the threat of such embargoes. "Every time a supplier thinks about raising the price of oil, the U.S. doesn't have to panic. We have a reserve of oil that protects this country from any short-term threat," says Linn. And the technologies developed to build the SPR can now work to improve technology and provide accurate information for other programs and industries. 团

For more information, call

James Linn, Underground Storage Technology, (505) 844-6813, or Jim Neal, Underground Storage Technology, (505) 844-7715. 


\section{Automated fixture design speeds development for prototypes and production}

Sandia engineers have developed a computer-aided design tool that creates fixture designs for finish machining, and assembly operations in manufacturing. Fixtures are essential elements in many manufacturing operations, and fixture design and development can be an expensive part of the manufacturing process. The Sandia program, called HoldFast ${ }^{\mathrm{TM}}$, produces multiple fixture designs to solve a given fixturing problem and ranks these designs using a quality metric.

Using HoldFast, manufacturers can design fixtures based upon fixture kits (for prototype or small-lot production) or based upon more permanent pallet-type structures, such as a tooling plate. Pallets are typically found in mass production environments, and might require a design that accommodates automated assembly processes. Sandia's fixture design program can support either fixture kits or permanent pallets with a globally optimal fixture design.

The fixture designs generated by HoldFast provide kinematic form closure: when a workpiece is held in the fixture, it cannot move unless either the part or the fixture elements deform. Generally, this means that three lateral locator pins will set the part in position to allow a side clamp to achieve horizontal form closure. Support pins beneath the workpiece, matched by swing-arm top clamps, can be part of the design when vertical movement is not permitted.

Manufacturers using HoldFast would provide inputs to the program, including a CAD definition of the workpiece requiring the fixture. Production personnel would also define the type of base plate (fixture kit or tooling plate) and the pins, clamps, and supports available, building a set of requirements that the program would use to construct possible fixture designs. HoldFast provides an interactive interface that permits operators to select an early high-quality fixture design without waiting for the program to present the globally optimal design for a particular workpiece. The program is even capable of providing fixture or pallet designs for mixed-part assembly, allowing use of the same pallet for two different parts at different times. This can provide production flexibility and save fixture production costs.

For more information, call:

Ralph Peters, Intelligent System Principles, (505) 845-0901, or Randy Brost, Intelligent System Principles, (505) 844-1336. 
This report was prepared as an account of work sponsored by an agency of the United States

Government. Neither the United States Government nor any agency thereof, nor any of their employees,

nor any of their contractors, subcontractors, or their employees, makes any warranty, express or implied, or assumes any legal liability or responsibility for the accuracy, completeness, or usefulness of any information, apparatus, product, or process disclosed, or represents that its use would not infringe privately owned rights. Reference herein to any specific commercial product, process, or service by trade name, . trademark, manufacturer, or otherwise, does not necessarily constitute or imply its endorsement, recommendation, or favoring by the United States Government, any agency thereof, or any of their contractors or subcontractors. The views and opinions expressed herein do not necessarily state or reflect those of the United States Government or any agency thereof, or any of their contractors or subcontractors.

Printed in the United States of America Available from:

National Technical Information Service U.S. Department of Commerce 5285 Port Royal Road . Springfield, Virginia- 22161

(703) $487-4600$

DOE Distribution Category UC900

$$
\checkmark
$$

This work was performed at Sandia National Laboratories, which is supported by the U.S. Department of Energy under contract DE-ACO4-94AL85000. 


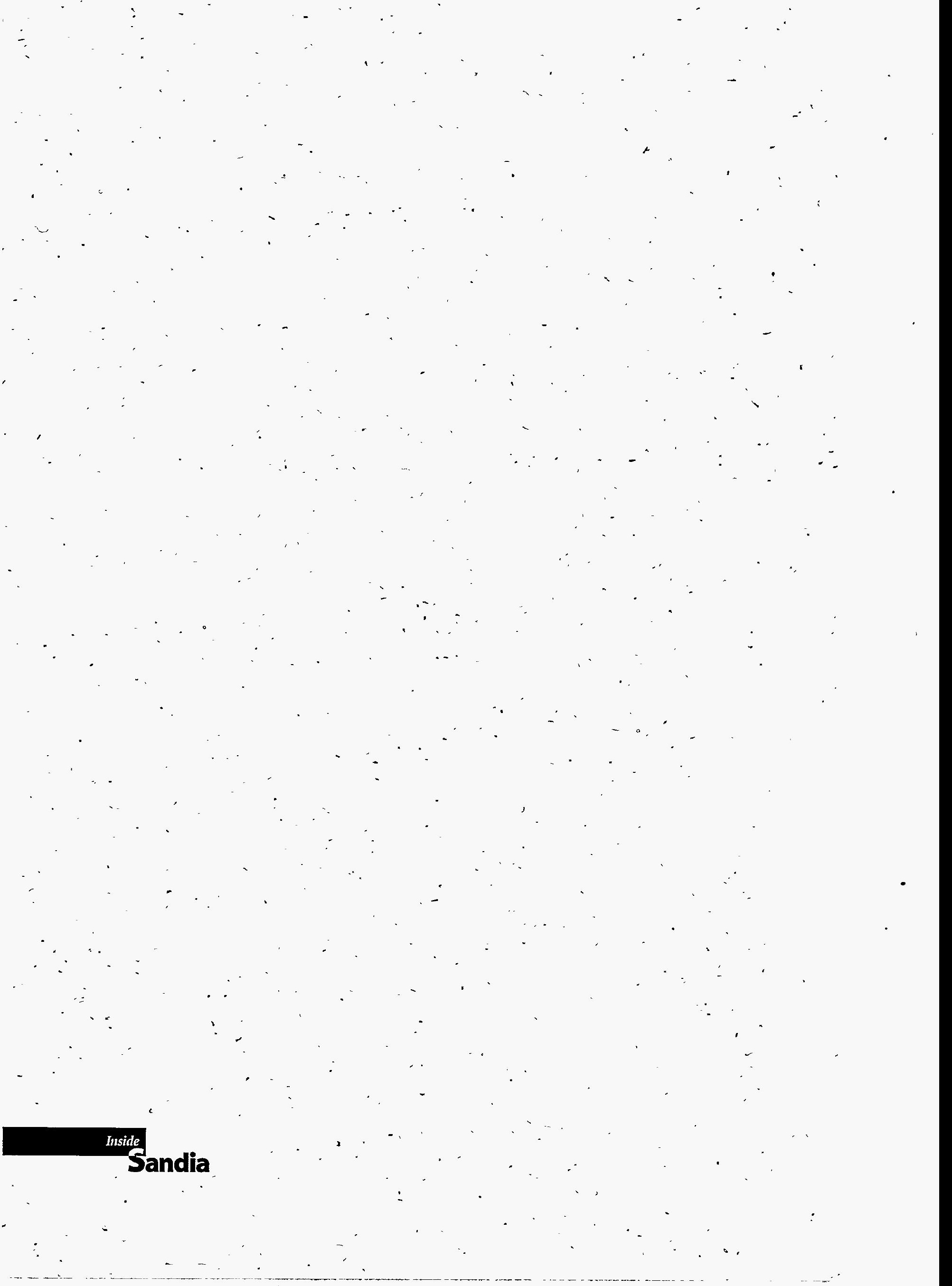

